\title{
STUDY OF REPARATIVE PROCESSES OF BONE TISSUE IN RATS USING OSTEOPLASTIC MATERIAL KLIPDENT PL WITH MEMBRANE KLIPDENT MK AND EASY-GRAFT MATERIAL WITH HYPROSORB MEMBRANE
}

\author{
Nikita Kravtsov \\ Department of children's dentistry, orthodontics and implantology \\ Kharkiv medical academy of postgraduate education \\ 58 Amosova str., Kharkiv, Ukraine, 61176 \\ Nikitafun@rambler.ru
}

\begin{abstract}
Acceleration of the reparative process of bone tissue after surgical interventions is an urgent issue in surgery and dentistry. One of the methods for replacing lost bone tissue is using an osteoplastic material. There is a question in the choice of better material, which will meet all the requirements of the doctor and fully perform its function. This work studies the activity of reparative processes of bone tissue in rats when the titanium screw is screwed into the femur using synthetic osteoplastic material Klipdent PL with membrane Klipdent MK ("Vladmiva" Russia) and Easy-graft material with Hyprosorb ("Sunstar" Swiss) membrane. The obtained results were compared with a control group in which the similar manipulation was performed without the use of an osteoplastic material. The experimental and morphological study was carried out. Conclusions are drawn about the effectiveness of the materials under study.
\end{abstract}

Keywords: osteoplastic material, bone tissue, stagnant defect, implant.

\section{Introduction}

Replacement of bone tissue sites after surgical interventions is an important task for the further rehabilitation of dental patients. Acceleration of reparative processes of bone tissue allows reducing the time of restoration of function and aesthetics, thereby positively affecting the patient's emotional state $[1,2]$.

The development of dental implantation occurs very quickly and with the advent of new techniques and tactics of treatment, the question arises of improving the recovery of bone tissue [3]. For this, various methods of reconstructive interventions are used, the result of which should be an increased or restored bone volume, necessary for optimal positioning and full functioning of the implants. One of the methods of reconstructive intervention in the maxillofacial area is directed on the bone regeneration, for which osteoplastic materials of various origins, such as synthetic, autografts or xenografts are used [4, 5]. The most widely used group of synthetic osteoplastic materials in view of its economic accessibility, the lack of access to the material of infected cells and high efficiency [6]. This group of osteoplastic materials has a stimulating effect on cell growth and promotes the activation of bone regeneration, contributes to the acceleration of the process of differentiation of the newly formed bone tissue. For successful passage of the process of bone tissue regeneration, along with osteoplastic material, special membranes consisting of restorative collagen type II, are used, which perform a barrier function and are able to integrate into the surrounding tissue without inducing an immune response [7, 8].

In connection with the emergence of many different materials, there is a need to identify the most effective drugs from the total number of products [9].

\section{Aim of research}

To study the activity of reparative processes in rats, when the implant is screwed into the femur, and using synthetic osteoplastic materials Klipdent PL with the membrane Klipdent MK and Easy-graft with Hyprosorb membrane after 30,60 and 90 days. To compare the results with the control group, in which a similar operation was performed to screw the implant into the femur of the animal, without the use of osteoplastic materials. 


\section{Material and methods of research}

In connection with the intended goal, an experiment on animals (white male, male floor) was carried out: 36 rats were divided into 3 groups (12 rats each), depending on the period of removal from the experiment: group I - 30 days, group II - 60 days, group III - 90 days. Each group was divided into three subgroups (4 rats each), depending on the material used: I subgroup - Klipdent PL with membrane Klipdent MK, II subgroup - Easy-graft material with Hyprosorb membrane, III subgroup - without the use of osteoplastic material (Table 1).

The studies were carried out in compliance with the International Principles of the European Convention for the Protection of Vertebrate Animals and in accordance with the "General Ethical Rules for Experiments on Animals" approved by the First National Congress on Bioethics on October 20, 2001 (Kiev) and the Law of Ukraine "On the Protection of Animals from Cruel Behavior "No. 3477-IV of February 21, 2006 [10].

Table 1

Structure of the experiment

\begin{tabular}{|c|c|c|c|c|c|c|c|c|c|}
\hline \multirow{3}{*}{ Groups of animals } & \multicolumn{9}{|c|}{32 rats } \\
\hline & \multicolumn{3}{|c|}{12} & \multicolumn{3}{|c|}{12} & \multicolumn{3}{|c|}{12} \\
\hline & 4 & 4 & 4 & 4 & 4 & 4 & 4 & 4 & 4 \\
\hline Used material & $\begin{array}{c}\mathrm{K} 1 \mathrm{Pl} \\
\mathrm{K} 1 \mathrm{Mk}\end{array}$ & $\begin{array}{l}\text { Eagt } \\
\text { Hyb }\end{array}$ & NoM & $\begin{array}{c}\mathrm{K} 1 \mathrm{Pl} \\
\mathrm{K} 1 \mathrm{Mk}\end{array}$ & $\begin{array}{l}\text { Eagt } \\
\text { Hyb }\end{array}$ & NoM & $\begin{array}{l}\mathrm{K} 1 \mathrm{Pl} \\
\mathrm{K} 1 \mathrm{Mk}\end{array}$ & $\begin{array}{l}\text { Eagt } \\
\text { Hyb }\end{array}$ & NoM \\
\hline $\begin{array}{c}\text { Terms of removal from } \\
\text { the experiment }\end{array}$ & & 30 days & & & 60 days & & & 90 days & \\
\hline
\end{tabular}

Note: KlPl-Klipdent PL; KlMk-Klipdent MK; Eagt-Easy-graft; Hyb-Hyprosorb; NoM-No material

Pre-rats were anesthetized, using "Ketamine" $(0.1 \mathrm{ml}$ of an official solution per $100 \mathrm{~g}$ of live weight). A defect was formed in the femur of the animal, with the help of carbide boron, into which the osteoplastic material was placed and a titanium screw was screwed. Considering the size of the femur bone, the self-tapping screws were selected individually, in order to avoid the assistance and fracture of the bone [11]. A membrane was placed on the top of the titanium self-tapping screw and the wound was sutured. A superposed seam connected the edges of the wound in their correct anatomical position, ensuring their adequate compression and minimum distance between them. This position was taken into account in accordance with the principles of work on the oral mucosa, where a minimally invasive approach is proposed in order to shorten the period of rehabilitation $[12,13]$.

During the entire period of the experiment, a satisfactory condition and absence of complications in animals were noted.

Each subgroup of animals was withdrawn from the experiment sequentially: I subgroup after - 30 days, II subgroup - after 60 days, III subgroup - after 90 days.

To remove animals from the experiment, they were sacrificed in accordance with the general ethical principles of animal experiments, an anesthetic overdose, the previously operated paw was separated and placed in a formalin solution, for subsequent morphological examination.

\section{Results of research}

In the first experimental group in which the material was used Klipdent PL with the Membrane Klipdent MK histological examination showed that changes, which can be characterized as destructive-inflammatory, were found on day 30. In the zone, adjacent to the bone defect (the location of the titanium self-tapping screw) the bone sites revealed focal edema, plethora of vessels and serous-fibrinous impregnation of bone structures and bone marrow spaces. Disorganization of bone trabeculae, desolation of a large part of cellular lacuna and even necrotic changes in bone tissue are noted, which is a manifestation of alteration (Fig. 1). Simultaneously with focal destructive-inflammatory changes, partial restoration of damaged and the formation of new tissue structures takes place. In the area of contact of the bone defect with the titanium screw and the 
osteoplastic material, the periosteum of the bone defect thickens considerably due to hyperplasia of the fibrous layer of the periosteum.

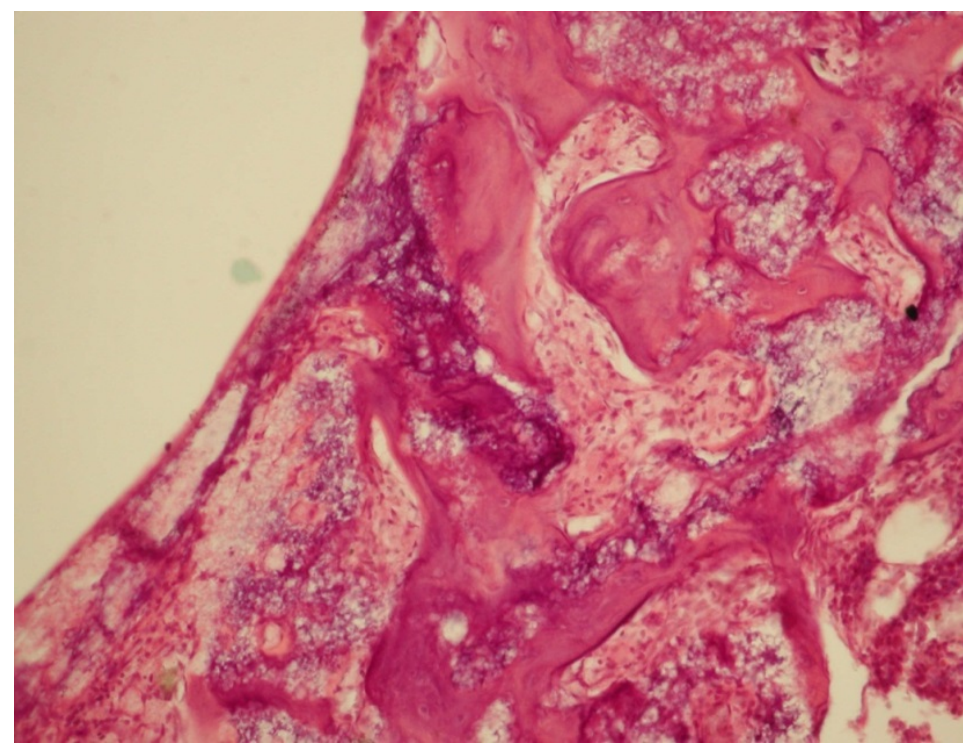

Fig. 1. Necrotic changes in bone tissue, serous-fibrinous impregnation of bone structures and bone marrow spaces. 30 days. Staining with hematoxylin and eosin. $\times 200$, Klipdent material

On the 60th day there is no widespread inflammatory infiltration in the part of observations, while the microcirculation is completely restored. The structure of the bone in the implantation site of the titanium self-tapping screw is characterized by the continued proliferation of connective tissue elements, the replacement of granulation tissue by the fields of the newly formed coarse-fibrous connective tissue with newly formed bone trabeculae. The newly formed bone tends to compacting, with a partial preservation of its coarse-fibrous character, it has areas with a high level of differentiation, up to the formation of osteons. In places in newly formed bone structures, bone marrow spaces are formed (Fig. 2).

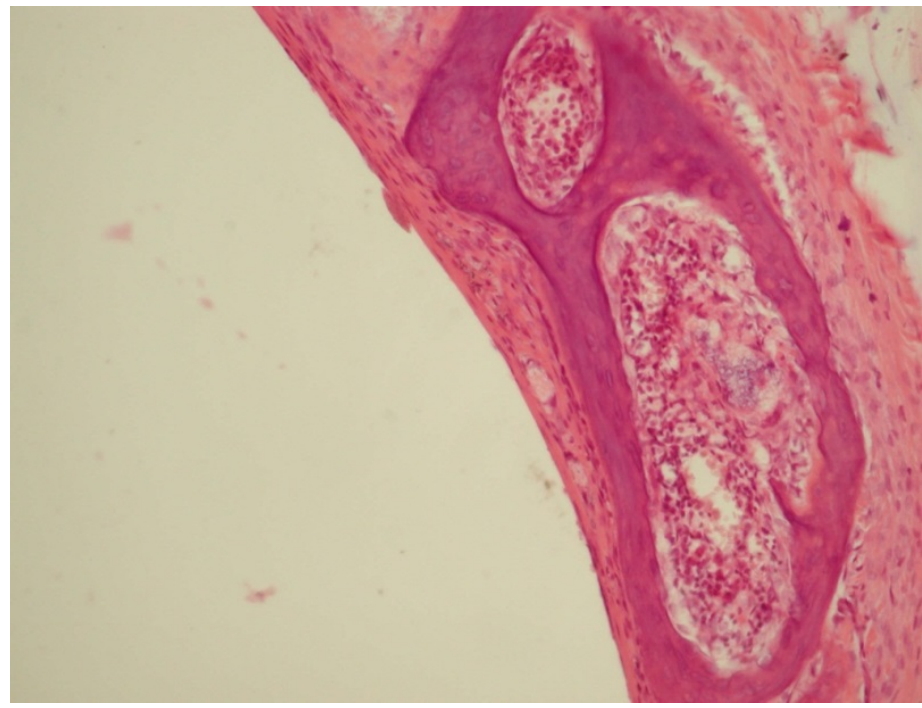

Fig. 2. Bone space in the newly formed bone trabeculae. 60 days. Staining with hematoxylin and eosin. $\times 200$, Klipdent material

On day 90 of the experiment the formation of newly formed bone material is practically completed, which at this stage is subjected to differentiation, resulting in turning it into a matrix 
of coarse fiber plate osteons developmental systems in which Haversian canals are visualized. The largest volume of newly formed bone is determined in the region adjacent to the titanium metal screws (Fig. 3). At the same time in the cancellous bone is marked correctly oriented arrangement of trabecular bone with the intervening medullary spaces.

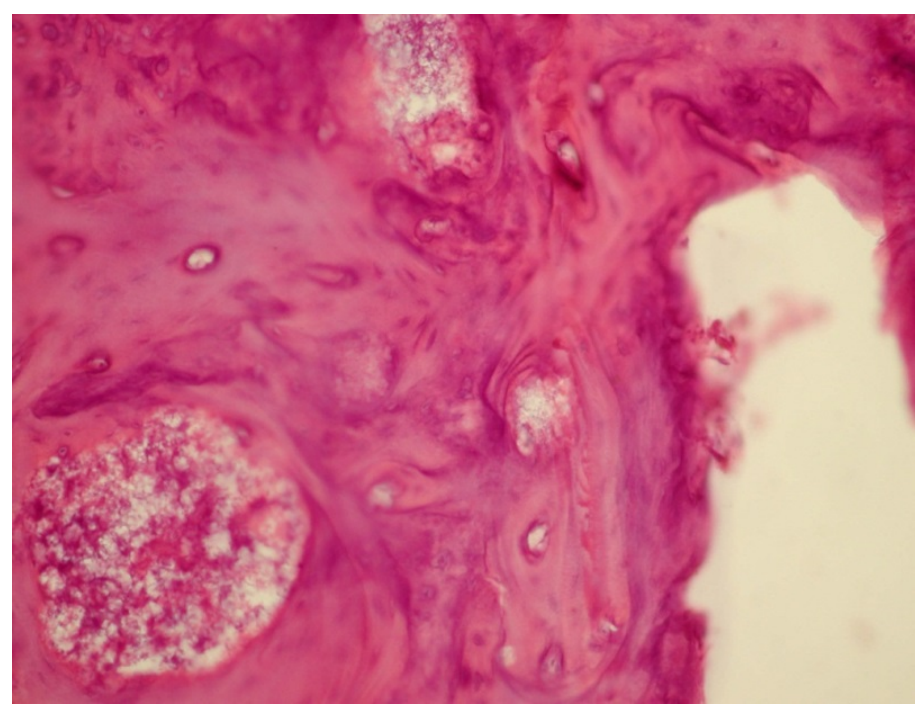

Fig. 3. In the newly formed bone numerous osteons are formed 90 days. Staining with hematoxylin and eosin. $\times 200$, Klipdent material

Thus, on the 90th day of the experiment, the formation and differentiation of the newly formed bone substance is completed, which is especially pronounced at the location of the samore and the implantation of the osteoplastic material.

In the second experimental group, which used Easy-graft material with the Hyprosorb membrane, a histological study showed that at 30 days, similar processes occur in the same way as in the first experimental group. Focal edema and serous-fibrinous impregnation of bone structures, disorganization of bone trabeculae are revealed. Serous-fibrinous impregnation of bone structures is observed (Fig. 4).

Thus, the morphological picture on the 30th day of the experiment confirms the reparative effect of the studied material, while the inflammatory necrotic changes are markedly expressed.

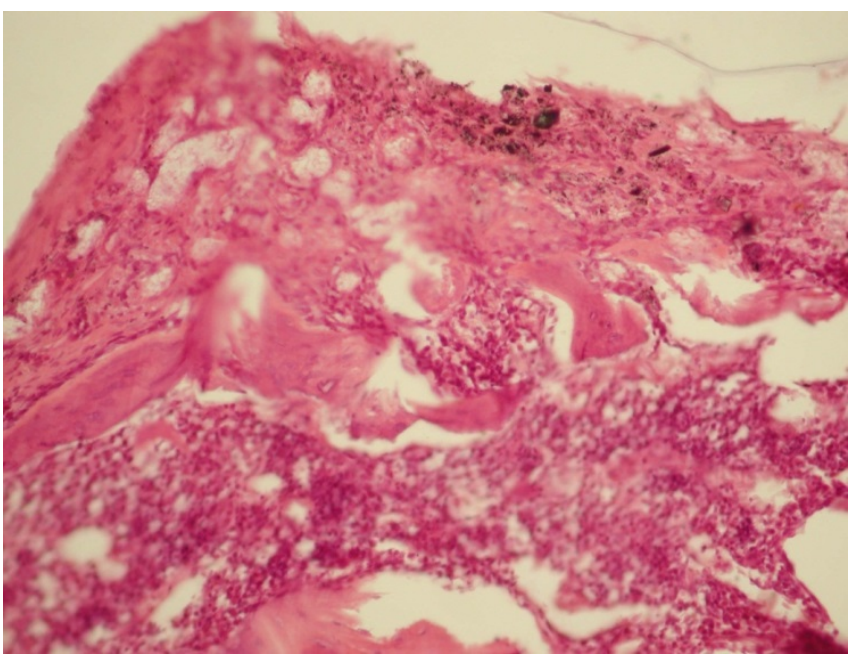

Fig. 4. Expressed necrotic changes in bone tissue. Bone marrow space with necrosis and serousfibrinous impregnation. 30 days. Staining with hematoxylin and eosin. $\times 200$, Easy-graft material 
On the 60th day there is no inflammatory infiltration, which (if focal) is common and preserved in the part of the observations, and a complete restoration of the microcirculation occurs. The structure of the bone in the implantation site of the titanium self-tapping screw is characterized by the continued proliferation of connective tissue elements, the replacement of granulation tissue by the fields of the newly formed coarse-fibrous connective tissue with newly formed bone trabeculae (Fig. 5).

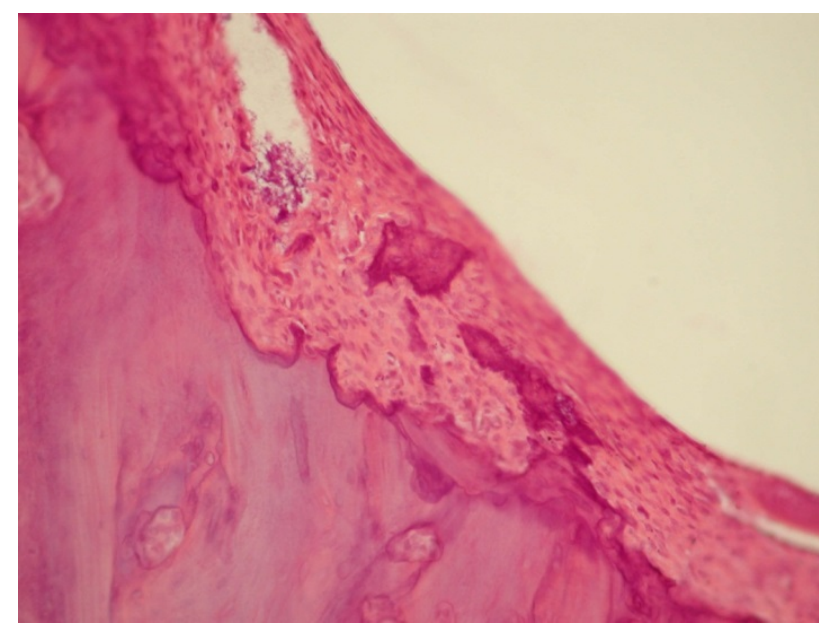

Fig. 5. Education in mature coarse-fibrous connective tissue, bone trabeculae. 60 days. Staining with hematoxylin and eosin. $\times 200$, Easy-graft material

Thus, on the 60th day of the experiment, the repair is enhanced, the coarse-fibrous connective tissue with ordered bundles of collagen fibers and with a large number of osteoblasts is formed, and bone structures are formed. The productivity of osteoplastic processes is poorly expressed.

On the 90th day of the experiment the formation of the newly formed bone substance is almost completed, which is differentiated at this stage (Fig. 6).

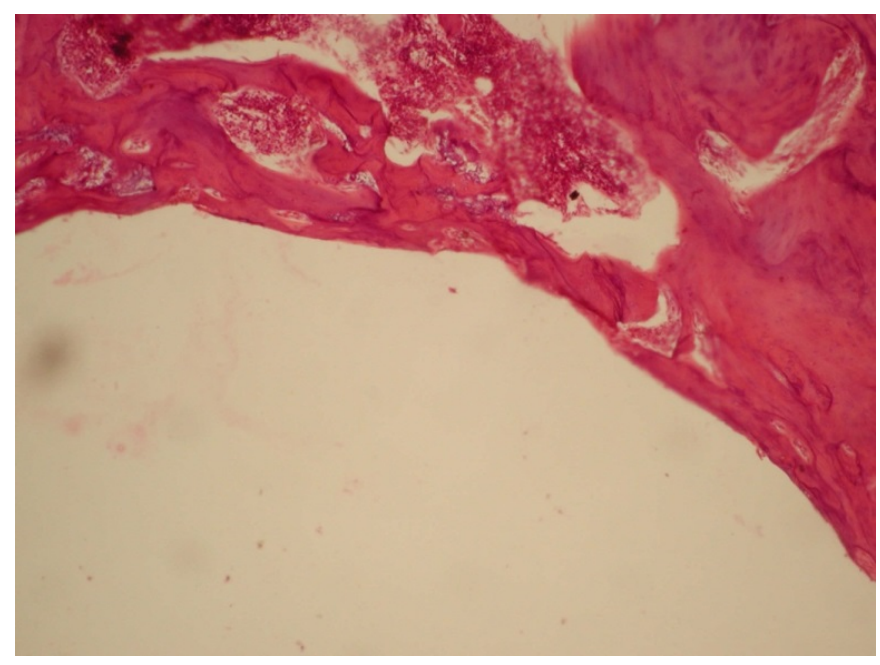

Fig. 6. A small volume of the newly formed bone tissue with poorly developed osteon systems.

The number of cellular elements of the osteoblastic series is reduced. 90 days.

Staining with hematoxylin and eosin. $\times 100$, Easy-graft material

On the 90th day of the experiment the formation and differentiation of the newly formed bone substance is completed, which is especially pronounced at the location of the implant and the implantation of the osteoplastic material. But the volume of the newly formed bone is small, there is a slight development of osteon systems, and the density of their location is characterized by unevenness. 
In the control group at all stages of the experiment, the reparative process is of low activity and is significantly delayed in comparison with the first and second experimental groups. Only on the 90th day on the edge of the bone defect is detected a meager regeneration, represented mainly by the fibrous-cellular or chondroitic tissue (Fig. 7-9).

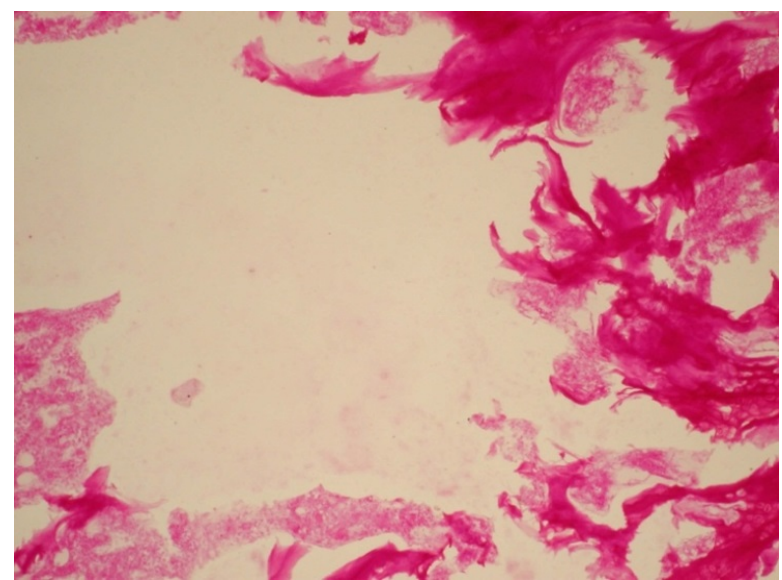

Fig. 7. Homogenization of the bone matrix, absence of lacunae, osteons and havers channels. 30 days. PAS-reaction. $\times 100$, without material

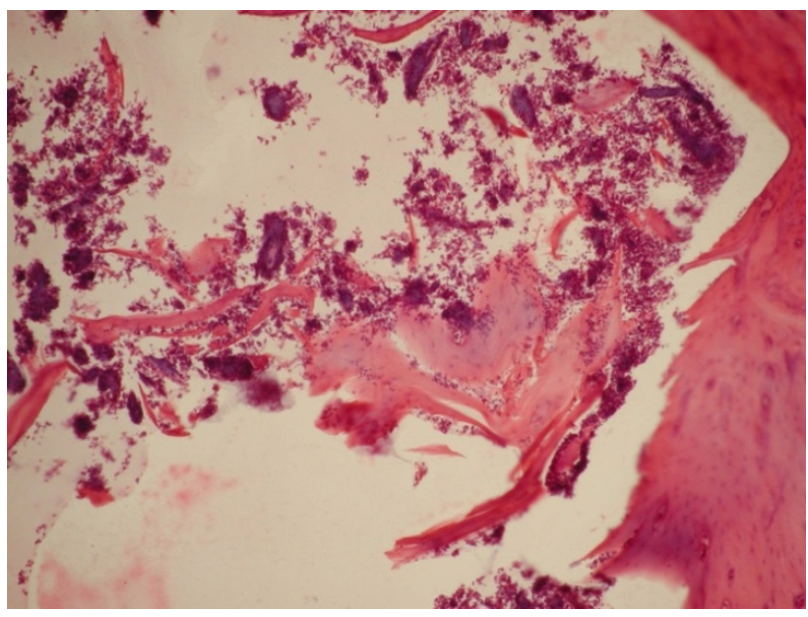

Fig. 8. A section of pre-existing necrotic bone tissue with empty lacunae and dystrophically altered osteocytes. 60 days. Staining with hematoxylin and eosin. $\times 100$, without material

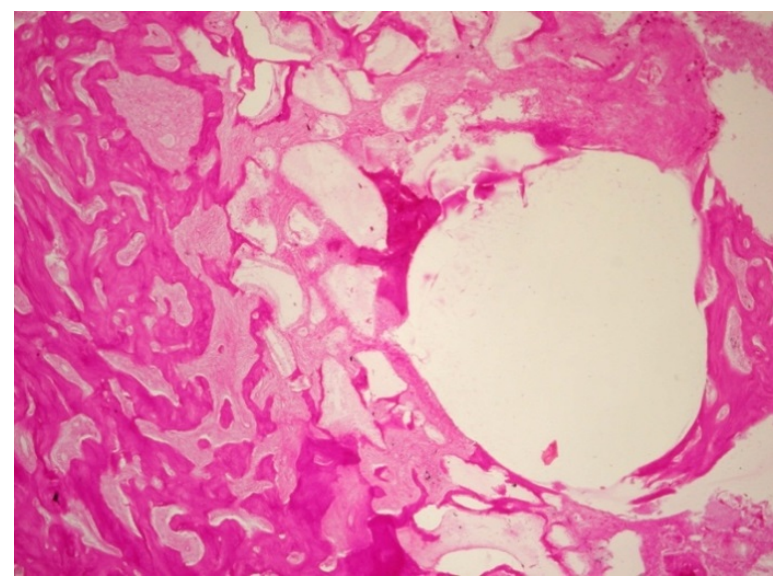

Fig. 9. Regenerate is represented by fibrous-cell tissue and a small number of thin bone bunches. 90 days. PAS-reaction. $\times 40$, without material 


\section{Discussion}

It is impossible to improve the techniques of dental implantation without improving the results of restoring the volume of the alveolar bone of jaws [14]. The search for methods and means of influence on reparative osteogenesis is currently continuing. At the moment there is not a large amount of literature and research devoted to the directed regeneration of bone tissue in dentistry, on this basis the need for experiments is the initial task [15].

Osteoplastic materials today occupy a worthy place in the practice of a dental surgeon. An animal study is under way to study reparative processes of the bone tissue at artificially created defects, using osteoplastic materials [16].

Comparing the results of the comparative morphological study, it can be concluded that the leading process at the location of the titanium self-tapping screw and the implantation of osteoplastic materials is the process of active osteogenesis both at the edges of the wound defect and in the sites of the location of bone fragments in the areas adjacent to the wound defect [17]. As the time of observation increases, the newly formed bone undergoes differentiation, the bone matrix from the coarse-fiber becomes lamellar, and the regeneration process ends with the intensive development of osteon systems $[18,19]$. Thus, the use of osteoplastic materials is not only a factor accelerating the healing process of the defect, but also a factor that serves to improve the character of the newly formed bone tissue [20].

Consequently, this study proves the effectiveness of using osteoplastic materials when it is necessary to perform the directed bone implantation in dentistry.

\section{Conclusions}

1. Thus, the results of the comparative experimental morphological study make it possible to conclude that the leading process at the location of the titanium self-tapping screw and the implantation of osteoplastic materials is the process of active osteogenesis both at the edges of the wound defect and in the sites of the location of bone fragments in the areas adjacent to the wound defect. As the time of observation increases, the newly formed bone undergoes differentiation, the bone matrix from the coarse-fiber becomes a plate, and the process of osteoregeneration is completed with the intensive development of osteon systems. At the same time, in the experimental group, where the osteoplastic material Klipdent PL and the membrane Klipdent MK were used, reparative osteogenesis is most optimal. The volume of newly formed bone structures is greater in the first experimental group, the newly formed bone substance with good qualitative characteristics. The main morphological difference from the second experimental group with the use of the Easy-graft osteoplastic material and the Hyprosorb membrane is a somewhat more pronounced local inflammatory and necrobiotic reaction at day 30 of the experiment. In the late stage of reparative osteogenesis, the volume of the newly formed bone is somewhat smaller, compared with the first experimental group, characterized by a weaker development of osteon systems and uneven location.

2. This work proves the effectiveness of the use of osteoplastic materials Klipdent PL and Easy-graft in the presence of directed clonal regeneration in rats. The experimental study allows to show visually to a doctor the stages of bone tissue regeneration (in a situation as close as possible to dental implantation) with the use of additional materials and without them.

\section{References}

[1] Ber, M. (2007). Elimination of complications of implant treatment, 289-290.

[2] Alfaro, F. H. (2007). Bone plastic surgery in dental implantology. Description of the methods and their clinical application. Moscow: Azbuka, 235.

[3] Kakachi, C., Neugebauer, J., Schlegel, A., Seidel, F. (2009). Handbook of Dental Implantology. Moscow: MEDPRESS-INFORM, 208.

[4] Manfred, L. (2008). Phantom course - simulator of dental implantation.

[5] Basic principles of implant surgery. Lviv: GalDent, 88.

[6] Sudnev, I., Mikhailov, I., Goldstein, E. (2007). Dental implantation. A new level of prosthetics. Saint Petersburg: OOO "MEDI Publishing House", 64. 
[7] Dahlin, C., Sennerby, L., Lekholm, U., Linde, A., Nyman, S. (1989). Generation of new bone around titanium implants using a membrane technique: An experimental study in rabbits. The International Journal of Oral \& Maxillofacial Implants, 4 (1), 19-25.

[8] Timofeev, A. A. (2007). Surgical methods of dental implantation. Kyiv: OOO "Chervona Ruta-Ture", 128.

[9] Fevraleva, A. Y., Davydian, A. L. (2008). Atlas of plastic soft tissue surgery around implants. Moscow: Poli Media Press, 264.

[10] Artzi, Z., Nemcovsky, C. E. (1998). The Application of Deproteinized Bovine Bone Mineral for Ridge Preservation Prior to Implantation. Clinical and Histological Observations in a Case Report. Journal of Periodontology, 69 (9), 1062-1067. doi: 10.1902/jop.1998.69.9.1062

[11] Hobkek, J. A., Watson, R. M., Sizn Lloyd, J. J. (2007). Manual on dental implantology. Moscow: MEDpress-Inform, 224.

[12] Kordaro, L., Terheiden, H. (2015). Reconstruction of the alveolar ridge during implant treatment. A phased approach. ITI, 7, 155.

[13] Antonio Baron, Ulf Nanmark. (2015). Regenerative technologies in dentistry. Moscow: Prakticheskaya medicina, 184.

[14] Terry, D., Geller, W. (2013). Aesthetic and restoration dentistry. Selection of materials and methods. Moscow: Azbuka Publishing House, 703.

[15] Adell, R., Lekholm, U., Rockler, B., Branemark, P.-I. (1981). A 15-year study of osseointegrated implants in the treatment of the edentulous jaw. International Journal of Oral Surgery, 10 (6), 387-416. doi: 10.1016/s0300-9785(81)80077-4

[16] Cohen, M. (2012). Interdisciplinary planning of dental treatment. Principles, objectives, practical application. Moscow: Azbuka Publishing House, 329.

[17] Khoury, F. et. al. (2014). Regenerative methods in implantology. Moscow: Azbuka Publishing House, 514.

[18] Ber, M., Missika, P., Giovagnoli, J.-L. (2007). Elimination of complications of implant treatment. Oral Surgery, 312-313.

[19] Zitsmann, N., Scherer, P. (2005). Dental rehabilitation with dental implants. Moscow: Azbuka Publishing House, 128.

[20] Alfaro, F. H. (2007). Bone plastic surgery in dental implantology. Description of the methods and their clinical application, 433.

[21] Maiorana, C., Simion, M. (2007). Advanced techniques for bone regeneration with Bio-Oss and Bio-Hyd. Moscow: Azbuka Publishing House, 211-212. 